\title{
EL PERÚ Y EL APEC: POR UNA MAYOR RELACIÓN ECONÓMICA CON LOS PAIISES DEL ASIA ORIENTAL
}

\section{Carlos Aquino Rodríguez}

El 20 y 21 de octubre del 2003 se reunieron en Tailandia los Líderes Económicos del APEC, el foro de Cooperación Económica Asia

Pacífico, que reúne a 21 economías de ambos lados de la Cuenca del Pacífico, del continente americano y asiático.

El Perú pertenece a este foro desde 1998.

El comercio del Perú con las economías del APEC representó el 50,4\% de nuestro comercio total en el 2002. La inversión extranjera desde los países del APEC representó el $26,24 \%$ de la inversión extranjera total acumulada en nuestro país en ese mismo año. Sin embargo, más de la mitad del comercio con las economías del APEC es con Estados Unidos y más del 65\% de la inversión desde las economías del APEC viene también desde Estados Unidos. Las economías asiáticas son 16 de las 21 economías del APEC; pero el comercio con esas economías en el año 2002 fue sólo un 19,4\% del total del comercio del Perú y la inversión desde ellos es un poco más del $2 \%$ del total de la inversión extranjera en nuestro país. Por eso la importancia de incrementar nuestra relación económica con la región asiática.

En el presente estudio se pasa revista al estado de las relaciones del Perú con las economías del APEC. Primero, se explica brevemente qué es el APEC y lo que significa para el Perú; segundo, vemos nuestra relación con los miembros americanos del APEC; tercero, nuestra relación con los miembros asiáticos del APEC, y, en cuarto y último lugar, vemos las conclusiones y recomendaciones para una mayor relación económica con nuestros socios en el APEC y los países asiáticos en particular. 


\section{1. ¿QUÉ ES EL APEC?}

El APEC, o foro de Cooperación Económica Asia Pacífico, fue creado en 1989 y actualmente reúne a 21 economías, ${ }^{1} 5$ en el continente americano y 16 en el lado asiático. En el lado americano están Canadá, Estados Unidos, México, Perú y Chile. En el lado asiático están: Japón, China, Corea del Sur, Taiwán (llamado Taipei, China), Hong Kong (ahora parte de China), Rusia, Australia, Nueva Zelandia, Brunej, Filipinas, Indonesia, Malasia, Singapur, Tailandia, Vietnam y Papúa Nueva Guinea. El APEC busca crear para el año 2020 una zona de libre comercio e inversiones entre sus miembros (en el 2010 liberalizarán su comercio e inversiones las economías más desarrolladas).

El APEC reúne a 21 economías que tienen en conjunto 2,5 mil millones de habitantes ( $42 \%$ del total mundial), un PBI combinado de US $\$ 19$ billones ( $55 \%$ del total mundial) y el $47 \%$ del comercio mundial (datos del año 2001). Este foro fue creado en 1989 pero desde 1994 se propuso tener una zona de libre comercio e inversiones para el año 2020. Desde 1993 se reúnen anualmente los Líderes Económicos para acordar nuevas direcciones en el objetivo del APEC, que es la liberalización del comercio y las inversiones; pero también la cooperación económica y técnica entre sus miembros.

Las decisiones para la liberalización del comercio y las inversiones se toman en el APEC en forma consensual y voluntaria. Esto se debe a la diversidad de sus miembros en cuanto a niveles de desarrollo económico. Por ejemplo, en el APEC están las economías más adelantadas del mundo como Estados Unidos y Japón, con elevados niveles de PBI per capita; por otro lado hay economías en pleno desarrollo como China y Vietnam, con aun un bajo nivel de PBI per capita. (Ver Cuadro N..$^{\circ}$ )

Como se ve, en el APEC están las dos economías más grandes del mundo, Estaclos Unidos y Japón, y la próxima economía más grande que será Chinā. Además, hay varios países en Asia que crecen a tasas aceleradas, como Corea del Sur e Indonesia y que representan grandes mercados.

\section{RELACIONES ECONÓMICAS CON LOS PAÍSES DEL CONTINENTE AMERICANO MIEMBROS DEL APEC}

De nuestros 20 socios comerciales en el APEC, cuatro están en este lado del Pacífico. Nuestra relación con Canadá, Estados Unidos, México (estos tres países miembros del Tratado de Libre Comercio de América del Norte) y Chile ha sido 
EL PERÚ Y EL APEC: POR UNA MAYOR RELACIÓN ECONÓMICA CON LOS PAÍSES DEL ASIA ORIENTAL.

Cuadro N. 1

Indicadores Económicos Selectos de las Economías del APEC Año 2002

\begin{tabular}{|c|c|c|c|c|}
\hline Países & $\begin{array}{c}\text { Población } \\
\text { millones }\end{array}$ & $\begin{array}{c}\text { Territorio } \\
\text { miles de } \mathrm{Km}^{2}\end{array}$ & $\begin{array}{c}\text { PBI per capita } \\
\text { dólares }\end{array}$ & $\begin{array}{l}\text { PBI en miles de } \\
\text { millones de dólares }\end{array}$ \\
\hline Australia & 19.1 & 7,682 & $\{8,42\}$ & 380 \\
\hline Brunei & 0.3 & 6 & 12,344 & 4 \\
\hline Canada & 30.8 & 9,971 & 22,694 & 717 \\
\hline Corea & 46.7 & 99 & 8,918 & 462 \\
\hline Chile & 15.2 & 757 & 4,315 & 76 \\
\hline China & 1.275 .1 & 9,561 & 919 & 1,080 \\
\hline Estados Unidos & 283.2 & 9,373 & 35,401 & 9,825 \\
\hline Filipinas & 75.7 & 300 & 926 & 75 \\
\hline Hong Kong & 6.9 & 1 & 24,080 & 162 \\
\hline Indonesia & 212.1 & 1,904 & 676 & 152 \\
\hline Japón & 127.1 & 378 & 37,299 & 4,765 \\
\hline Malasia & 22.2 & 333 & 3,891 & 90 \\
\hline México & 98.9 & 1,973 & 6,072 & 581 \\
\hline Nueva Zelanda & 3.8 & 271 & 13,111 & 51 \\
\hline Papúa Nueva Guinea & 4.8 & 463 & 620 & 4 \\
\hline Peru & 25.7 & 1,285 & 2,051 & 54 \\
\hline Rusia & 145.5 & 17,075 & 2,147 & 260 \\
\hline Singapur & 4.0 & 1 & 20,738 & 93 \\
\hline Tailandia & 62.8 & 513 & 1,825 & 122 \\
\hline Taiwán & 22.2 & 36 & 12,599 & 309 \\
\hline Vietnam & 78.1 & 331 & 418 & 31 \\
\hline
\end{tabular}

Fuente: "Economic Indicators for APEC Member Economies". APEC web site: www.apecsec.org.sg.

tradicionalmente bastante antigua y mayor: $y$ se ha acrecentado en la última década.

Como se ve en los Cuadros N. 2 y 3 , en la última década nuestra relación comercial con estos países aumentó bastante, tanto por el lado de las exportaciones 
como de las importaciones. Por el lado de nuestras exportaciones a estos 4 países, éstas crecieron y pasaron de representar el $28, .21 \%$ del total exportado al mundo en 1993 a representar el 32,61\% en el 2002. El más grande mercado es Estados Unidos y su importancia aumentó en los últimos años y en el año 2002 fue el destino del $25,8 \%$ de todo lo vendido por el Perú al exterior (en 1993 sólo el 20,8\% de nuestras ventas fueron alli). Nuestras ventas a Chile también han aumentado en gran medida, más de 3 veces entre 1993 y el 2002. Exportamos a estos países principalmente materias primas; pero también textiles y otros productos de algún valor agregado.

\section{Cuadro N. ${ }^{\circ} 2$}

Comercio Exterior del Perú con 4 Países Americanos del APEC (1) (en millones de dólares)

Exportaciones (FOB)

\begin{tabular}{|l|c|c|}
\cline { 2 - 3 } & \multicolumn{1}{c|}{1993} & 2002 \\
\hline Total mundlal & $3,344.40$ & $7,608.24$ \\
\hline Canadá & 93.88 & 140.24 \\
\hline Estados Unidos & 695.62 & $1,962.12$ \\
\hline Mexico & 91.03 & 129.66 \\
\hline Chile & 72.94 & 249.66 \\
\hline Total 4 paises & 943.47 & $2,481.76$ \\
\hline (\% del total mundial) & 28.21 & 32.61 \\
\hline
\end{tabular}

Fuente: Aduanas del Perú: página web: uww.aduanet.gob.pe.

Por el lado de nuestras importaciones desde estos países, ésta también aumentó, aunque la importancia relativa de estos países en el contexto global decayó un poco en la última década. En 1993 del total de nuestras compras del exterior, el 35,62\% venía de esos países, en el 2002 de ellos vino el 29,87\% del total importado. Les compramos mayormente maquinarias, insumos y bienes de consumo: en suma, productos manufacturados. Nuestro déficit comercial con estos países se convirtió en superávit en la última década (la razón es que el gran déficit comercial que teníamos con Estados Unidos ahora se ha convertido en un superávit, de más de US $\$ 500$ millones en el año 2002).

Por el lado de la inversión desde estos países, como se ve en el Cuadro $\mathrm{N}^{\circ} 4$, el monto aumentó grandemente en la década pasada, aunque a un menor ritmo que el aumento de la inversión extranjera total en el país. De 1993 al 2002 la 
EL PERÚ Y EL APEC: POR UNA MAYOR RELACIÓN ECONÓMICA CON LOS PAÍSES DEL.

ASIA ORIENTAL

inversión extranjera total acumulada en nuestro país pasó de US \$ 1641 millones a US \$11536 millones; esto es un aumento de más de 7 veces, pero la inversión total de estos 4 países en el Perú aumentó en sólo casi 4 veces. Por esta razón, la importancia relativa de estos países en la inversión total en nuestro país pasa de un $44,34 \%$ en el año 1993 a un $24,07 \%$ en el 2002 .

\section{Cuadro $\mathrm{N}^{\circ} 3$}

Comercio Exterior del Perú con 4 Paises Americanos del APEC (II) (en millones de dólares)

Exportaciones (CIF)

\begin{tabular}{|l|c|c|}
\cline { 2 - 3 } \multicolumn{1}{c|}{} & $\mathbf{1 9 9 3}$ & $\mathbf{2 0 0 2}$ \\
\hline Total mundial & $4,024.55$ & $7,485.89$ \\
\hline Canadá & 56.81 & 121.64 \\
\hline Estados Unidos & $1,109.68$ & $1,471.94$ \\
\hline México & 111.07 & 278.42 \\
\hline Chile & 156.05 & 418.78 \\
\hline Total 4 países & $1,433.61$ & $2,236.78$ \\
\hline (\% del Total mundial) & 35.62 & 29.87 \\
\hline
\end{tabular}

Fuente: Aduanas del Perú. Página web: www.aduanet.gob.pe.

Cuadro N. ${ }^{\circ} 4$

Inversión Extranjera Directa Registrada en el Perú desde 4 Paises Americanos del APEC Monto acumulado a diciembre de cada año

(en millones de dólares)

\begin{tabular}{|l|c|c|}
\cline { 2 - 3 } \multicolumn{1}{c|}{} & 1993 & 2002 \\
\hline Total mundial & $1,641.38$ & $11,536.0$ \\
\hline Canada & 35.29 & 160.4 \\
\hline Estados unidos & 653.10 & $1,982.2$ \\
\hline Mexico & 0.38 & 36.8 \\
\hline Chile & 39.12 & 597.5 \\
\hline Total 4 paises & 727.89 & $2,776.9$ \\
\hline (\% del Total mundial) & 44.34 & 24.07 \\
\hline
\end{tabular}

Fuente: Proinvesion. Página web: www mef.gob.pe/peruinv/. 
La inversión desde algunos de estos países sí aumentó en forma importante. Por ejemplo, el aumento desde Chile fue de 15 veces. La inversión desde Estados Unidos, de US \$ 1982 millones en el 2002, representa el 17,18\% de la inversión extranjera total en el país (y el $65 \%$ de la inversión desde las economías del APEC). En el 2002 una cuarta parte de ese monto fue al sector energía, otra cuarta parte al sector minero, un séptimo al sector financiero y un poco menos de ese monto al sector industrial.

\section{RELACIONES ECONÓMICAS Y POLÍTICAS CON LOS PAÍSES ASIÁTICOS MIEMBROS DEL APEC}

Nuestra relación comercial con los 16 países asiáticos del APEC (del Asia Oriental) es todavía menor. Para poder examinar mejor esta relación dividiremos a estos países en dos grupos, primero un grupo de 8 países más grandes y con los que el Perú tiene una relación comercial y política más antigua y después el resto de países. Los 8 países más grandes son Japón, China, Corea del Sur, Taiwán, Hong Kong, Rusia, Australia y Nueva Zelandia. Nuestra relación con el resto de países, como Brunei, Filipinas, Indonesia, Malasia, Singapur, Tailandia, Vietnam y Papúa Nueva Guinea se analizará más adelante.

\subsection{Relación comercial y política con los 8 países asiáticos más grandes}

Estos 8 países o economías están entre los más desarrollados del Asia Oriental, con varios de ellos, como Japón, Australia, Hong Kong y_Nueva Zelandia, entre los más avanzados en el mundo. (Ver Cuadro N. ${ }^{\circ} 1$ )

Nuestra relación con algunos de estos países se remonta a 1844 cuando se inició la inmigración china al Perú y a 1899 cuando empieza la inmigración japonesa. Como resultado de ello, actualmente nuestro país tiene la mayor presencia de descendientes chinos en Latinoamérica y la tercera mayor de descendientes japoneses en el mundo (después de Brasil y Estados Unidos).

En 1873 el Perú estableció relaciones diplomáticas con Japón y en el ạno siguiente con China (fue el primer país latinoamericano en establecer relaciones diplomáticas con estos países asiáticos). Estos dos países son los más importantes en la región asiática y con los cuales el Perú mantiene la mayor relación comercial y política (otro país importante es Rusia, pero con el cual nuestra relación comerciales aún menor). 
ASIA ORIENTAL

Antes de la Segunda Guerra Mundial nuestra relación comercial con la región asiática se limitaba sólo a la relación con Japón. A partir de la década del 20 nuestra balanza comercial con este país, de un monto bastante menor comparada con otros países, se volvió deficitaria. En la década del 30 frente a las importaciones baratas de textiles japoneses y ante la queja de los productores peruanos, el gobierno impone una cuota a la importación de productos japoneses. El inicio de la Segunda Guerra Mundial deteriora las relaciones con el país nipón y el comercio con este país prácticamente se detiene.

En la década del 50 se reinician las relaciones diplomáticas con Japón y hacia la década del 60 este pás se convierte ya en un importante socio comercial del Perú. En esta década también se establecen las primeras empresas japonesas en el país como Ajinomoto y Matsushita. Esta relación se consolida durante el gobierno militar de la década del 70 cuando Japón pasa a ser el segundo socio comercial del Perú después de Estados Unidos El comercio entre el Perú y Japón aumenta y hacia 1975 por ejemplo este comercio global totaliza casi US $\$ 360$ millones, de los cuales US \$152 millones fueron lo que el Perú exportó y US \$208 millones fueron importaciones. Si bien se tuvo un déficit comercial este año, esto fue más bien inusual puesto que tradicionalmente se tenía un superávit comercial con Japón (todos las cifras sobre comercio exterior del Perú antes de 1990 son tomadas del libro de Víctor Torres Cuzcano: El Perúfrente a la Cuenca del Pacífico, 1991).

La década del gobierno militar sirvió también para iniciar o reiniciar relaciones diplomáticas con Rusia y China. Las relaciones con Rusia fueron afianzadas por la compra de armamentos que el Perú comenzó a realizar en esta década desde ese país y que se ha mantenido desde entonces. Con China, en noviembre de 1971 se establecen relaciones diplomáticas y comienza el comercio con este país. Sin embargo, la relación comercial con estos dos países era bastante menor en este período.

En esta misma década, del 70, sobre todo en la segunda mitad, el comercio con Australia y Nueva Zelandia era de algunas decenas de millones de dólares en ciertos años y en todo caso en esta década, después de Japón, estos dos países fueron para el Perú los socios comerciales más importantes en Asia.

En la década de 1980 al entrar la economía peruana en crisis y específicamente desde la segunda mitad, cuando el país suspendió muchos de sus pagos a sus acreedores extranjeros, nuestra relación económica con Japón se estancó. Por ejemplo, los pagos a ese país por el préstamo que dio para la construcción del Oleoducto Norperuano (en la década del 70) se retrasaron y por 
esto no hubo nuevos préstamos de Japón y tampoco nueva inversión de sus empresas en el país. Ello, unido al clima de inseguridad por el fenómeno terrorista imperante en nuestro país, ahuyentó a varias empresas niponas del país. Sin embargo, nuestro comercio (exportaciones más importaciones) siguió una dinámica algo diferente y las exportaciones a Japón subieron en esta década por la boyante economía japonesa; pero por otro lado nuestras importaciones cayeron por la economía peruana deprimida. Así, nuestras exportaciones fueron de US $\$ 335$ millones en 1980 y de US $\$ 419$ millones en 1990 , mientras que las importaciones pasaron de US \$288 millones a US \$ 82 millones en ese mismo lapso.

En el caso de la relación comercial con los otros países, la magnitud de ésta era menor en esta década. Con Rusia, con el cual teníamos una deuda importante por la compra de armamentos, la compra adicional de estos equipos se detuvo y más bien se intentó pagar parte de la cleuda contraída exportando algunos productos no tradicionales, pero esto fue bastante limitado y en montos menores.

Con China, Taiwán y Corea del Sur en la década de 1980 comienza a crecer el comercio bilateral. Con China el comercio aumento rápidamente y en 1985 el comercio total fue de US $\$ 79$ millones, de los cuales US $\$ 77$ millones fueron exportaciones nuestras. Con Taiwán ya desde 1970 se tenía algún comercio en el que se importaba algunos productos manufacturados y se les vendía materias primas y este comercio fue creciendo año tras año (en 1975 el comercio total había sido de US \$ 19 millones, de los cuales US \$ 18 millones fueron compras nuestras). En el año 1980 este comercio llega a ser por un monto de US $\$ 114$ millones, de los cuales US \$66 millones fueron exportaciones peruanas. Con Corea del Sur también el comercio aumenta en la década de 1980 y en 1985 éste alcanzó un monto global de US $\$ 89$ millones, de los cuales US $\$ 84$ millones fueron exportaciones peruanas a ese país. En todo caso, en la década de 1980 el Perú tenía un superávit comercial con todos estos países.

Sin embargo, en esta década con Australia y Nueva Zelandia se tuvo un déficit comercial, aunque el monto del comercio total era bastante menor. Por ejemplo, en 1980 de un intercambio total de US \$16 millones con Australia, US \$11 millones eran importaciones del Perú. En el caso de Nueva Zelandia, de un intercambio total de US $\$ 30$ millones en 1980 , US $\$ 29,4$ millones eran compras peruanas. En todo caso, en la década de 1980 el monto del comercio con estos países estuvo por detrás del comercio con Japón, China, Taiwán y Corea. 


\subsection{Relación comercial y política de 1990 en adelante}

La elección en 1990 de Alberto Fujimori como Presidente del Perú sirvió para dar impulso a las relaciones del país con la región asiática. Fujimori, de ascendencia japonesa, puso especial énfasis en afianzar nuestra relación con Japón y con los demás países asiáticos llegando a viajar a los países de esa región más de 15 veces durante su mandato de 10 años y visitando en ese lapso la mayoría de ellos. Antes de Fujimori sólo un presidente peruano, Manuel Prado, había hecho un viaje a Asia, específicamente a Japón, en la década del 50.

La mayor relación del Perú con los países del Asia Oriental que se da a partir de 1990 se enmarca dentro de una estrategia del país para diversificar sus relaciones comerciales y para aprovechar el potencial que representan los países de esa región. Asimismo, se buscó incorporarse al APEC, donde están las economías más dinámicas de la Cuenca del Pacífico. Como paso previo en 1991 el Perú logra incorporarse al Consejo de Cooperación Económica del Pacífico, PECC, y un poco antes al Consejo Económico de la Cuenca del Pacífico, PBEC. El PECC es un órgano tripartito (participan académicos, empresarios y funcionarios de gobierno) y el PBEC es un organismo donde se reúnen los hombres de negocios de la región. Todas las economías miembros del APEC están tanto en el PECC como en el PBEC.

Con Japón aumentó especialmente la cooperación económica que ese país brinda al Perú. Japón fue uno de los países que ayudó al Perú a reintegrarse a la comunidad financiera internacional a la cual nuestro país prácticamente había dejado de pertenecer desde la segunda mitad de la década del 80 . Después, Japón ha prestado un importante monto de dinero al país. A marzo del 2003 el monto acumulado de cooperación económica comprometida de Japón al Perú es de US $\$$ 4000 millones (a julio de 1990, cuando ingreso Alberto Fujimori como Presidente, el monto desembolsado era de menos de US $\$ 500$ millones).

Como se ve, la cooperación económica de Japón al Perú aumento enormemente en la década de 1990, es decir, la ayuda oficial de gobierno a gobiemo (que comprende prestamos reembolsables y no reembolsables, esto último donaciones y cooperación técnica). Sin embargo, nuestro comercio con el país nipón y las inversiones desde ese país al nuestro no aumentaron y se han estancado (excepto las importaciones que hacemos desde Japón que sí han subido, ver Cuadros N. ${ }^{\circ}$ 5, 6, y 7). En 1993 se importó por US $\$ 303$ millones y en el 2002 por US $\$ 406$ millones. En cuanto a exportaciones, el año 2002 el Perú vendió a Japón por US $\$ 374$ millones, monto inferior a lo que se vendió en 1990 que fue de US \$ 
419 millones (en realidad el monto vendido en el 2002 era sólo mayor en $15 \%$ a lo que se exportó en 1980, veintidós años antes, que fue de US \$335 millones). La razón es que el Perú sigue exportando mayormente materias primas a ese país y éstas fluctúan de precio en el tiempo. En el 2002, el Perú tuvo un déficit comercial con Japón por US $\$ 32$ millones.

Cuadro N. 5

Comercio Exterior del Perú con 8 Paises Asiáticos más Grandes (en millones de dólares)

Exportaciones (FOB)

\begin{tabular}{|c|c|c|}
\cline { 2 - 3 } & \multicolumn{1}{c|}{$\mathbf{1 9 9 3}$} & $\mathbf{2 0 0 4}$ \\
\hline Total mundial & $\mathbf{3 , 3 4 4 . 4 0}$ & $\mathbf{7 , 6 0 8 . 2 4}$ \\
\hline Australia & 14.99 & 34.59 \\
\hline Cored del Sur & 59.36 & 168.08 \\
\hline Chra & 140.84 & 597.60 \\
\hline Hong Kong & 28.60 & 32.12 \\
\hline Japon & 299.04 & 374.38 \\
\hline Nueva Zelanda & 1.50 & 3.11 \\
\hline Rusia & 9.90 & 23.90 \\
\hline Tawan & 118.78 & 110.37 \\
\hline Total 8 paises & 673.01 & $1,344.23$ \\
\hline (\% del Total mundial) & 20.12 & 17.66 \\
\hline
\end{tabular}

Fuente: Proinversion. Página web: www.mef.gob.pelperuinv/.

Por el lado de las inversion mipnis. éstas aumentaron muy poco, pasando de un total acumulado de US $\$ 37,9$ millones a US $\$ 101,1$ millones en el lapso 1993-2002. El 50\% de esta inversión está en el sector minero y el $34 \%$ en el sector industrial. La razón para esta poca inversión es el clima de inseguridad que aún sienten algunos japoneses en el Perú y las pocas oportunidades de inversión que encuentran en el país. Hay que señalar, sin embargo, que estas cifras son de inversiones hechas directamente por empresas japonesas, pero hay otras inversiones hechas en el Perú por capitales japoneses a través de otras empresas, trabajando en consorcio con ellas. Por ejemplo, hay participación japonesa asociada con capitales de otros países en la Refinería de Zinc de Cajamarquilla y en las operaciones de la mina de Antamina (en esta última participa el Grupo Mitsubishi).

Con China sí aumentó en forma importante el comercio y la inversión en la década pasada. En 1990 se exportó a este país sólo US \$55 millones, en 1993 se 
EL PERÚ Y EL APEC: POR UNA MAYOR RELACIÓN ECONÓMICA CON LOS PAÍSES DEL. ASLA ORIENTAL

Cuadro $\mathrm{N}^{\circ} 6$

Comercio Exterior del Perú con 8 Países Asiáticos más Grandes (en millones de dólares)

Importaciones (CIF)

\begin{tabular}{|c|c|c|}
\cline { 2 - 3 } & \multicolumn{1}{c|}{1993} & 2004 \\
\hline Total mundial & $4,024.55$ & $7,485.89$ \\
\hline Australia & 17.35 & 25.18 \\
\hline Corea del Sur & 99.42 & 229.33 \\
\hline China & 90.43 & 465.00 \\
\hline Hong Kong & 12.29 & 12.56 \\
\hline Japon & 303.62 & 406.55 \\
\hline Nueva Zelanda & 45.95 & 22.56 \\
\hline Rusia & 15.28 & 36.29 \\
\hline Talwan & 60.16 & 118.13 \\
\hline Total 8 paises & 644.50 & $1,315.60$ \\
\hline (\% del Total mundial) & 16.01 & 17.57 \\
\hline
\end{tabular}

Fuente: Proinversion. Página web: www.mef.gob.pe/peruinvl.

incrementó a US \$140 millones y en el 2002 el Perú le vendió por US $\$ 597$ millones, monto mayor ińcluso a lo que se exportó a Japón (US \$374 millones en este último año). Desde 1996 China se ha convertido en el mayor mercado para nuestros productos en Asia, desplazando a Japón. Lo que es más importante, mantenemos con China un superávit comercial, algo que hemos perdido con Japón y Corea del Sur. China es el principal mercado para nuestras exportaciones de harina de pescado y hierro. El monto total del comercio con China es bastante mayor del que tenemos con Japón. En el 2002 este monto fue de US \$1062 millones con China y de US $\$ 780$ millones con Japón. China ha pasado a ser nuestro mayor socio comercial en Asia y el segundo en el mundo después de Estados Unidos

Por el lado de las inversiones de China al Perú, en 1990 ésta era inexistente. En diciembre de 1992 la empresa china Shougang Corp. compra la empresa estatal Hierro Perú invirtiendo alrededor de US $\$ 120$ millones. Lamentablemente, después no ha habido mayor inversión y a fines del 2002 la inversión china acumulada en el país era de sólo US $\$ 122$ millones, monto sin embargo mayor al de Japón y la más importante de los países de la región asiática. (Ver Cuadro $\mathrm{N}^{-7}$ )

En el caso de Corea del Sur, de 1990 en adelante el comercio con este país aumentó en forma muy rápida. Especialmente nuestras importaciones desde Corea 
aumentaron al abrirse el mercado peruano a importaciones baratas del mundo. Productos de ese país, como automóviles y artefactos electrónicos, han desplazado a los productos japoneses, pues son más baratos. Autos como el Tico de la compañía Daewoo y los televisores Samsung se han hecho populares en el país. En 1990 el comercio global con Corea era de US \$83 millones; fue de US \$ 159 millones en 1993 y este monto paso a US $\$ 397$ millones en el 2002 , convirtiéndose así este país en el tercer socio comercial del Perú en la región asiática. En la década de 1990 nuestro comercio se volvió deficitario con Corea y en el 2002, por ejemplo, se exportó a ese país US $\$ 168$ millones pero le compramos por US $\$ 229$ millones. Por otro lado, la inversión coreana, inexistente en 1990, llegó a un acumulado de US \$ 20,7 millones a fines del año 2002.

Cuadro N. ${ }^{\circ} 7$

Inversión Extranjera al Perú desde 8 países asiáticos más grandes Monto acumulado a diciembre de cada año

(en millones de dólares)

\begin{tabular}{|l|c|c|}
\cline { 2 - 3 } \multicolumn{1}{c|}{} & 1993 & 2004 \\
\hline Total mundial & $1,641.38$ & $11,536.00$ \\
\hline Corea del Sur & 0.01 & -- \\
\hline China & 118.08 & 20.70 \\
\hline Hong Kong & 0.00 & - \\
\hline Japon & - & 101.10 \\
\hline Nueva Zelanda & 37.96 & 6.85 \\
\hline Rusla & 0.00 & - \\
\hline Taiwan & 0.19 & - \\
\hline Total 8 paises & --20 & 250.85 \\
\hline (\% del Total mundial) & 156.24 & 2.17 \\
\hline
\end{tabular}

Fuente: Proinversion, pagina web: www.mef.gob.pe/peruinv/.

El comercio con Taiwán también se incrementó en esta década y en el 2002 alcanzó un monto total de US $\$ 228$ millones, de los cuales US\$110 millones fueron nuestras exportaciones. Con los demás países el comercio se incrementó pero en una menor proporción. Vendemos más a Australia, luego sigue Hong Kong, Rusia y Nueva Zelandia. La inversión desde estos países es mínima o inexistente. Con Rusia 
otra vez en la década de 1990 nuestra relación comercial aumentó por la compra de. equipos militares desde este país (aunque el monto transado en estas operaciones no aparece en las estadísticas de comercio exterior).

\subsection{Perspectivas de nuestra relación con estos 8 países}

En 1998 el Perú se une al APEC con lo que se abrió una oportunidad para aumentar nuestras relaciones económicas con estos 8 países. El Perú tiene una buena relación política con estos países y tenemos misiones diplomáticas en todos ellos. Estos países también tienen misiones diplomáticas en el nuestro, aunque no todos tienen embajadas aquí (Australia por ejemplo sólo tiene consulado general, reabierto hace cuatro años).

Nuestro comercio global con estos 8 países es aún menor. En el año 2002 las ventas a estos países representaron el $17,66 \%$ del total de nuestras exportaciones al mundo y nuestras compras de ellos el $17, .57 \%$ de nuestras importaciones totales. Si recordamos que en 1993 las ventas a estos países representaban el $20,1 \%$ del total vendido al exterior vemos que hemos retrocedido pues ahora les vendemos relativamente menos que hace 9 años. En cuanto al comportamiento de nuestras importaciones, en 1993 el monto de nuestras compras desde estos países asiáticos representaron alrededor de un $16 \%$ de nuestras importaciones totales, figura sólo un poco menor a la del año 2002. Teníamos un superávit comercial con estos países en 1993 y en el 2002 ello se mantiene. Por el lado de la inversión extranjera desde esos países, ésta representó a fines del 2002 sólo el 2,1\% de la inversión extranjera total acumulada en nuestro país (a fines del año 1993 llegó a representar el 9,5\% del total acumulado).

Considerando el gran mercado que representan estos países y los grandes flujos de capital que varios de ellos invierten en el extranjero, nuestra relación comercial con estos países es aún bastante menor. Sobre todo consideremos que China cada vez exporta e importa más. Por ejemplo, en 1978, antes del inicio de sus reformas económicas China exportó por US \$9955 millones e importó por US \$11 131 millones. En el año 2002, China exportó por US \$325 591 millones e importo por US \$295 171 millones. China este año o el próximo sobrepasará a Japón como el segundo exportador en el mundo y a Estados Unidos lo pasará en los próximos 3 ó. 4 años para convertirse en el primero. Como importador, como el mayor mercado del mundo para los productos extranjeros, China lo será probablemente en los próximos 4 ó 5 años, sobrepasando a Estados Unidos ya que dicho país compra de todo. 
China, recordemos, es ahora nuestro mayor mercado en Asia y el segundo en el mundo; pero debemos venderle no sólo materias primas.

\subsection{Relación económica y política con otros países asiáticos}

Los otros países asiáticos miembros del APEC son Brunei, Filipinas, Indonesia, Malasia, Singapur, Tailandia, Vietnam y Papúa Nueva Guinea. Los siete primeros pertenecen al grupo ASEAN o la Asociación de Naciones del Sudeste Asiático (que tienen 10 miembros en total). Describiremos brevemente lo que es ASEAN y Papúa Nueva Guinea y después veremos la relación de todos estos países conelPerú.

ASEAN fue fundada el 8 de agosto de 1967. En la Declaración de Bangkok (Tailandia) de este grupo de diciembre de ese ańo, fueron 5 los países cuyos Ministros de Relaciones Exteriores firmaron el acuerdo inicial: Filipinas, Indonesia, Malasia, Singapur y Tailandia. Más tarde, en 1984, se unió Brunei, en 1995 Vietnam, en 1997 lo hacen Laos y Myanmar y finalmente en 1999 se une Camboya llegando asía 10 el número de países miembros.

ASEAN nació en 1967 como un grupo que buscaba hacer un frente unificado a la amenaza de la creciente expansión del comunismo en el Sudeste Asiático. En ese entonces la guerra de Vietnam estaba en pleno apogeo y los 5 paises miembros originales veían en el accionar de Vietnam del Norte la expansión del comunismo hacia el Sur, con el peligro de que Vietnam del Sur, Laos, Myanmar (en ese entonces Birmania) y Camboya caigan en manos del comunismo y después le toque el turno a Tailandia y los demás países del Sudeste Asiático miembros de ASEAN. En los primeros años de este grupo su accionar fue eminentemente político. Por ejemplo, en 1971 los Ministros de Relaciones Exteriores de ASEAN emiten una declaración para hacer de esta región una Zona de Paz, Libertad y Neutralidad en su reunión de Kuala Lumpur, en Malasia. También en 1976 en la Primera Cita Cumbre de ASEAN en Bali, Indonesia, los líderes de los 5 países firman un Tratado de Amistad y Cooperación en el Sudeste Asiático para reforzar la unidad frente al peligro comunista en la región.

A partir de la década de 1980 el énfasis del grupo de ASEAN cambia a uno de buscar una unidad de criterios para incrementar el comercio y la cooperación económica entre sus miembros. Así, en 1987 en la Tercera Cita Cumbre de ASEAN, celebrada en Manila, Filipinas, se declara la intención de buscar una mayor cooperación en los campos político, económico, social y en el desarrollo humano. 

ASLA ORIENTAL

Finalmente, en julio de 1992 en la Cuarta Cita Cumbre de Singapur, los lideres de ASEAN acuerdan establecer el AFTA, esto es, un Área de Libre Comercio en ASEAN (AFTA, de las siglas en inglés ASEAN Free Trade Area). Esto debe llevarse a cabo a través de un cronograma de aceleradas reducciones de aranceles entre los países miembros en el esquema de adoptar un Arancel Preferente Efectivo Común (Common Effective Preferential Tariff Scheme). Se busca crear un área de libre comercio en un mercado de 500 millones de habitantes para que las empresas aprovechen las economías de escala, se genere más competencia y se atraiga más inversión extranjera. En septiembre de 1994 se acordó que el período para alcanzar el área de libre comercio en la región se reduzca del plazo original de 15 a 10 años. Esto es, para el 2003 el arancel entre los países de la ASEAN sería de entre $0 \%$ a $5 \%$.

Los países de ASEAN, específicamente los cinco originales, alcanzaron en las tres últimas décadas un crecimiento económico acelerado. Vietnam se unió a este desarrollo acelerado desde 1987 cuando adopta reformas económicas para dejar atrás su sistema de economía socialista. Esto es lo que le ha permitido ingresar al ASEAN en 1995, donde estaban los países que temían la expansión del comunismo que justamente el accionar de Vietnam representaba. Sin embargo la crisis asiática, desatada en 1997, que se inició justamente en julio de ese año en Tailandia, afectó seriamente al grupo.

A seis años de la crisis asiática los países de ASEAN se están recuperando, unos más rápido que otros. El país que tiene más problemas es Indonesia pues allí el problema económico se combina con el político, donde hay inestabilidad. Indonesia fue el país más afectado por la crisis asiática y pasaran algunos años más para que su economía recupere su nivel de antes de la crisis. Los demás países poco a poco se están recuperando, con Singapur, el más adelantado en la región, prácticamente ya recuperado. La fiebre de la neumonía atípica afectó el turismo y los negocios en la región este año pero ya se han recuperado.

Hay que destacar que los países de ASEAN conforman un grupo diverso en cuanto a niveles de desarrollo económico, tamaño territorial, población y dotación de recursos naturales (ver a los países de ASEAN como Brunei, Filipinas, Indonesia, Malasia, Singapur, Tailandia y Vietnam en el Cuadro N. ${ }^{\circ}$ 1). Así, Singapur y Brunei tienen un alto nivel de PBI per cápita, arriba de los US $\$ 10$ mil anuales, mientras por otro lado los ex países socialistas como Laos, Myanmar, Camboya y Vietnam tienen un PBI per cápita de menos de US $\$ 420$ anuales y en sus economías el sector agrícola es aún el más importante. Aun más, Singapur y Brunei (excepto petróleo este último) no tienen casi recursos naturales, mientras que el resto de los países lo 
tienen y en forma abundante. La diferencia en tamaño de población y territorio también es grande como se ve en el Cuadro N. 1. Justamente este carácter de los países de ASEAN hace que los acuerdos sobre diversos temas de integración política yeconómica se tomen en forma consensual entre sus miembros.

Finalmente, hay que señalar que algunos países, especialmente Malasia, Indonesia, Filipinas y Tailandia, se parecen bastante al Perú. Son similares al tener como el Perú también una abundante dotación de recursos naturales, un nivel de desarrollo económico semejante, así como en la heterogeneidad de su población (con diversas razas conviviendo en el país). Sin embargo, Malasia que haca, 30 años tenía incluso un nivel de désarrollo económico menor al nuestro de ese entonces, en este período ha avanzado muchísimo sobrepasando al Perú en muchas áreas, como en el del desarrollo industrial y exportador.

En el caso de Papúa Nueva Guinea, éste es un país de un bajo nivel de desarrollo económico, dependiente de la explotación de recursos naturales como oro, níquel, petróleo, agricultura y pesca.

\subsection{Relaciones económicas y políticas con el grupo ASEAN y Papúa Nueva Guinea}

En la década de 1980 teníamos algo de comercio con Singapur y la magnitud de éste era de algunas decenas de millones de dólares en algunos años, generalmente compras nuestras (por ejemplo importamos de ese país por US $\$ 11,3$ millones en 1980 y por US $\$ 5,8$ millones en 1985 ). Con Filipinas también hubo algo de comercio, ucasionalmente de algunos millones de dólares en algún año, casi siempre ventas nuestras (por ejemplo le vendimos US \$ 4 millones en 1985 y US $\$ 13,4$ millones en 1990). Hacia fines de esta década se empezó a comerciar con Vietnam y Tailandia, generalmente compras nuestras de arroz desde estos países. En todo caso en 1990 el comercio con el grupo de ASEAN no llegabà en total a US $\$ 50$ millones (exportaciones más importaciones). En el año 2002 este monto fue de US $\$ 230$ millones.

En el 2002 nuestras exportaciones a este grupo de prises fueron de US $\$ 35.8$ millones y nurstras importaciones deste estegrupo fueron de US $\$ 144.3$ millones. listo represento respectivimente of $1.12^{\prime \prime}$ clel total de nuestras "xportaciomes y el 1.92"" del hold de nuestres importaciones. (Ver Cuadro N." 8 y Cuntron." 
EL PERÚ Y EL APEC: POR UNA MAYOR RELACIÓN ECONÓMICA CON LOS PAÍSES DEL ASIA ORIENTAL

\section{Cuadro $\mathrm{N}:{ }^{\circ} 8$}

Comercio Exterior del Perú con los Paises de ASEAN y Papua Nueva Guinea (I) (en millones de dólares)

Exportaciones (FOB)

\begin{tabular}{|c|c|c|}
\hline & 1993 & 2002 \\
\hline Total mundial & $3,344,40$ & $7,608.24$ \\
\hline Brunet & 0.00 & - \\
\hline Camboya & 0.00 & - \\
\hline Indonesia & 12.30 & 25.01 \\
\hline Laos & 0.90 & 0.00 \\
\hline Malasia & 26.57 & 9.34 \\
\hline Myanmar & 0.02 & - \\
\hline Filpinas & 24.04 & 13.98 \\
\hline Singapur & 1.10 & 6.71 \\
\hline Tallandla & 0.81 & 26.02 \\
\hline Vielnam & 0.18 & 4.67 \\
\hline Papua Nueva Guinea & 0.40 & 0.08 \\
\hline Total ASEAN & 65.96 & 85.81 \\
\hline$\%$ del Total mundal & 1.97 & 1.12 \\
\hline
\end{tabular}

Fuente: Aduanas del Perú. Página web: www.aduanet.gob.pe.

El monto del comercio con ASEAN se ha incrementando de año en año. De los países de ASEAN el socio más importantes es Indonesia. En el año 2002 el comercio total con este país fue de US \$59 millones (en el año 1990 había sido de US \$ 10 millones y en el año 1993 de US \$ 15 millones), representando la cuarta parte del comercio total con este grupo; los otros socios importantes son Tailandia, Malasia y Filipinas, esta situación se ha mantenido a lo largo de la última década. Por otro lado, el comercio con Brunei, Camboya, Laos y Myanmar es casi inexistente.

Exportamos a todos estos países generalmente harina de pescado y algunos minerales como estaño, zinc y cobre. Esto representa más del $90 \%$ de nuestras ventas. Por otro lado, importamos de estos países principalmente maquinas y aparatos de oficina, artefactos eléctricos, partes y accesorios de equipo de transporte. En el 2002 tuvimos un déficit comercial con estos países de US $\$ 59$ millones.

Con Papúa Nueva Guinea tenemos un comercio casi inexistente. Antes de 1990 las relaciones políticas y diplomáticas con los países del grupo de ASEAN y Papúa Nueva Guinea era escasa o inexistente. En la última década se dieron una serie de acercamientos con estos países que han resultado en el establecimiento de embaiadas de nuestro país en varios de ellos y también en las 
Cuadro $N .^{\circ} 9$

Comercio Exterior del Perú con los Paises de ASEAN y Papua Nueva Guinea (11)

(en millones de dólares)

Importaciones (CIF)

\begin{tabular}{|l|c|c|}
\cline { 2 - 3 } & \multicolumn{1}{c|}{$\mathbf{1 9 9 3}$} & $\mathbf{2 0 0 2}$ \\
\hline Total mundial & 4.024 .55 & 7.485 .89 \\
\hline Brunei & 0.01 & 0.00 \\
\hline Camboya & 0.00 & 0.00 \\
\hline Indonesia & 3.69 & 34.70 \\
\hline Laos & 0.00 & 0.04 \\
\hline Malasia & 5.34 & 46.74 \\
\hline Myanmar & 0.06 & 0.01 \\
\hline Filipinas & 0.33 & 6.94 \\
\hline Singapur & 10.54 & 22.96 \\
\hline Tailandia & 21.36 & 29.70 \\
\hline Vietnam & 33.87 & 3.19 \\
\hline Papua Nueva Guinea & -- & - \\
\hline Total ASEAN & 75.23 & 144.28 \\
\hline$\%$ del Total mundial & 1.86 & 1.92 \\
\hline
\end{tabular}

Fuente: Aduanas del Peru. Página web: mww aduanet gob.pe.

visitas que dignatarios de esos países han realizado al Perú y del Perú hacia esos países.

Por ejemplo, ahora tenemos embajadas del Perú en Malasia, Tailandia, Filipinas, Singapur e Indonesia (aunque en los últimos meses el gobierno peruano anunció que cerraría la Embajada en Filipinas por cuestiones presupuestarias). Desde estos países se cubren la representación a los otros, por ejemplo, de Singapur se cubre a Brunei y de Tailandia a Vietnam (desde Australia se cubre a Papúa Nueva Guinea). En la última década también se observó la visita, por primera vez, de un presidente peruano a la mayoría de los países de ASEAN. En los últimos 10 años el ex presidente Alberto Fujimori Fujimori visitó Malasia, Táilandia, Indonesia, Filipinas, Singapur, Bruner y Vietnam.

Por parte de estos prises asiáticis también en la década de 1990 se ha chservades un mayer acercamientes al Perú. Per ejemples aherea hay una Embajada

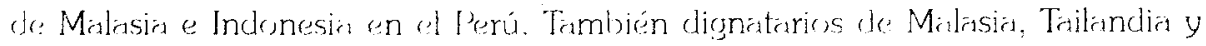
Vietnam han visitade nuestre pais. Esteracercamiente del Pere a ASEAN se enmarcó

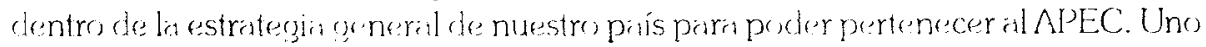

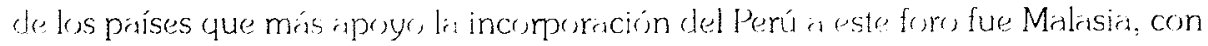


EL PERÚ Y EL APEC: POR UNA MAYOR RELACIÓN ECONÓMICA CON LOS PAÍSES DEL.

ASIA ORIENTAL

quien se estrecho relaciones en la última década. En el APEC participan la mayoría de los países de ASEAN. Así, en este foro junto al Perú están 7 de los 10 países de ASEAN. Éstos son: Brunei, Filipinas, Indonesia, Malasia, Singapur, Tailandia y Vietnam.

\subsection{Perspectivas en las relaciones del Perú con ASEAN y Papúa Nueva Guinea}

La mayoría de los países de ASEAN tienen una estructura económica similar a la del Perú, con un nivel de desarrollo similar y con dotación de recursos también similar. Esto no favorece mucho el intercambio comercial entre el Perú y este grupo si se produce y exporta lo mismo, generalmente productos de poco valor agregado. Sin embargo, hay países como Filipinas, Indonesia, Malasia, Tailandia y Singapur que se están desarrollando rápidamente y que producen y exportan bienes con valor agregado. No es casualidad por eso que tenemos un mayor intercambio comercial con estos países. No obstante, generalmente les exportamos materias primas e importamos de ellos productos industriales. Debería procurarse exportar productos con valor agregado desde el Perú, como textiles, ropa de algodón y de lanas de camélidos peruanos, productos agroindustriales, conservas de pescado, etc., puesto que en esos países existe una creciente clase media que demanda estos productos. Hay que estudiar estos mercados y saber específicamente qué se les puede vender.

El comercio seguirá creciendo con ASEAN en la medida que ellos crezcan y demanden más materias primas de nuestro país. Especialmente la demanda por harina de pescado’y minerales seguirá creciendo. Asimismo, ellos cada vez fabrican más barato productos como artefactos eléctricos, material de transporte, ropa y zapatos. Así, el Perú seguirá aumentando la compra de estos productos desde esos países (aunque tendrán que competir con China que cada vez produce más barato esos mismos productos).

Por el lado de la inversión de los países de ASEAN al Perú, por el momento prácticamente ésta no existe. Sin embargo, Malasia ha mostrado interés en participar en el desarrollo hotelero y forestal del país. De hecho hay alguna participación de un grupo económico de este país en dos o tres hoteles en el Cusco. Asimismo, ha habido visitas de especialistas de Malasia a ver el proyecto de desarrollo de la Amazonia peruana. Podría aprovecharse la experiencia exitosa de este país en la explotación de la palma aceitera, caucho, madera, etc. 
En el plano político y diplomático es necesario afianzar más estas relaciones. Los países de ASEAN conforman un mercado muy importante de 500 millones de habitantes, que será uno solo en pocos años mas. Debemos conocer este mercado más. Las misiones diplomáticas. del Perú en estos países deben ser reforzadas con personal capacitado en temas comerciales que puedan brindar a nuestros empresarios información sobre esos mercados.

El Perú y los países de ASEAN están juntos en el APEC. Además, existe la iniciativa de estrechar las relaciones de ASEAN con la Comunidad Andina, al cual el Perú pertenece. De hecho en mayo del 2000 se realizó en Bangkok la primera reunión entre estos dos grupos. Se acordó realizar una segunda reunión en Lima el año 2001 (que la final no se realizó). Todo esto, más la conformación del Foro de Latinoamérica y el Este Asiático, en el que participan tanto el Perú como los países de ASEAN, brindan instancias en las que se presentan oportunidades para una creciente relación entre nuestro país y los de la Asociación de Naciones del Sudeste Asiático.

Con Papứa Nueva Guinea nuestra relación es bastante menor y la seguirá siendo en el futuro previsible. Este país participa poco de las reuniones del APEC y además no tiene mucho qué vender o comprar del Perú.

\section{CONCLUSIONES Y RECOMENDACIONES}

El APEC es uno de los grupos más importantes en el mundo y al pertenecer el Perú a este foro se nos abre la oportunidad de aprovechar los grandes mercados de esta región de la Cuenca del Pacífico. Para aprovechar mejor nuestra participación en el APEC se debería en general:

1. Mejorar la infraestructura física y de transportes y comunicaciones para hacer negocios con los integrantes de la Cuenca del Pacífico, especialmente con los países asiáticos. Por ejemplo, una política de cielos abiertos para poder tener una ruta alterna para volar hacia Asia por el Hemisferio Sur y no como ahora que sólo hay vuelos por el Hemisferio Norte (pasando por Estados Unidos). Existe la posibilidad de comprometer a líneas aéreas de Asia a volar hacia el Perú por el Hemisferio Sur, a través del Atlántico Sur, como se hace desde Chile y Argentina. También hay que mejorar el transporte terrestre, por ejemplo los puertos en el Sur del Perú con Bolivia y Brasil, para que el Perú sea realmente el puente entre América del Sur y el mercado asiático, rol que Chile ya lo está tomando. Al ser el Perú el único país de la Comunidad Andina en el APEC podría ser un puente entre ellos. Asimismo el Perú últimamente se ha convertido en socio del MERCOSUR: 
2. Hay que concluir acuerdos de protección de inversiones con algunos países del APEC con los cuales aún no lo hemos hecho. Tenemos acuerdos ya con Estados Unidos, Chile, Australia, Corea, China, Malasia, Tailandia y Singapur; pero aún nos falta con varios países de Asia. De tener estos acuerdos podríamos atraer más inversiones-desde esos países. Japón y Taiwán por ejemplo invierten miles de millones de dólares al año en el mundo, pero en el Perú es mínima esta inversión (inexistente en el caso de Taiwán).

3. En general, se requiere una mejor coordinación entre el Estado y las empresas privadas con el objetivo de vender más al exterior. Las instituciones del Estado como Prompex y PROMPERÚ deberían coordinar con el sector privado para ver qué se vende y qué se promociona del Perú y atraer así mayor inversión y turismo de nuestros socios del APEC. La participación del sector privado en el APEC es fundamental. Las empresas privadas son al final las que invierten, compran y venden. Son las que arriesgan en los negocios y deberían contar con el apoyo correspondiente.

4. El APEC es un foro que requiere la participación en muchas reuniones. Esto es costoso y además no tenemos los suficientes cuadros técnicos, así que tenemos que priorizar algunas áreas de interés para nuestro país, como el turismo, la promoción de comercio e inversiones, pesquería y la cooperación económica y técnica.

5. También el esfuerzo de lograr un mayor beneficio para el Perú de su participación en el APEC tiene que ver con un esfuerzo conjunto del sector gobierno, empresariál y el académico. Conocer la realidad de los países asiáticos es fundamental para poder planear una estrategia diplomática, política y económica de integración con esa región. Lo mismo vale para que las empresas puedan colocarsus productos pues es necesario conocer bien esos mercados y la idiosincrasia de sus consumidores.

6. Por último, el APEC también es un mecanismo que promueve la cooperación económica y técnica entre sus miembros. Este es un mecanismo poco utilizado aún por nuestro país. Existe el Subcomité ECOTECH o de Cooperación Económica y Técnica del APEC. Debemos aprovechar este mecanismo para obtener cooperación económica y técnica de otros miembros del APEC en el tema del desarrollo de, por ejemplo, las PYMES, el Desarrollo de Recursos Humanos, el Desarrollo Agrícola, etc. Especialmente en estos campos los países asiáticos, como Japón, Corea y Taiwán, tienen mucho que ofrecer.

Por otro lado, en particular con los 16 países del Asia Oriental que pertenecen al APEC y con los cuales nuestra relación comercial es aún menor, se requiere mayor atención nuestra. En el año 2002 sólo el 18,7\% de nuestras exportaciones fueron a estos países (en 1993 esta cifra fue de $22,1 \%$ ) y el $19,5 \%$ de 
nuestras importaciones vinieron de esos países (en 1993 esta cifra fue de 17,8\%). Del total de inversión extranjera acumulada en el Perú a fines del año 2002, sólo el $2,17 \%$ (US $\$ 250$ millones) vinieron de estos países (en 1993 de los países asiáticos vino el $9,51 \%$ del total). Hay aún mucho margen para aumentar nuestra relación comercial con estos países. Lo que pasa es que no conocemos sus mercados y muchas veces no tenemos oferta exportable sobre lo que ellos quieren comprar. $\mathrm{El}$ $90 \%$ de lo que vendemos a los asiáticos son materias primas (la misma situación de hace 20 ó 30 años). Los países asiáticos cada vez compran más productos del extranjero. Japón por ejemplo aumentó tres veces sus compras del exterior en el período 1985-2002 y China siete veces en ese mismo lapso. El Perú en ese período aumentó poco sus ventas a Japón pues no ofrecemos lo que los japoneses quieren (alimentos, manufacturas, etc.) y a China sí aumentamos pero ,casi sólo materias primas.

Entonces hay que aumentar nuestra oferta exportable y para ello debemos conocer qué es lo que los asiáticos demandan. Asimismo, empresas peruanas deberian asociarse con empresas de Asia para poder venderles más. Para esto se requiere también de un ambiente seguro y estable para la inversión asiática, que aumentó muy poco en el Perú de 1993 en adelante. Se requiere estabilidad económica, jurídica, política y social para atraer inversiones que produzcan para la exportación.

Debería también incentivarse la participación del sector privado en este foro, que es justamente uno de los objetivos del APEC. Asimismo, el gobierno debería convertir las misiones diplomáticas en el exterior en oficinas comerciales que faciliten información a los asiáticos sobre los productos que el Perú ofrece y que por otro lado brinden información a los empresarios peruanos sobre lo que el mercado asiático demanda. Sólo así aprovecharemos el creciente mercado asiático, que con el APEC se abrirá completamente al Perú en el año 2020 (el año 2010 abrirán sus mercados los países más desarrollados en este grupo). Hay que prepararnos para ello pués sino seguiremos vendiéndole los mismos productos, cada vez de menor valor agregado y más bien ellos aumentarán sus ventas al Perú. Tradicionalmente teníamos un superávit comercial con los países asiáticos, ahora esto no es así. El año 2002 tuvimos un déficit comercial global con esta región de US $\$ 60$ millones y ello tenderá a aumentar cada vez más. El mercado asiático es promisorio, pero hay que saber cómo aprovecharlo.

Por último, mantenemos una buena relación diplomática y política con los países asiáticos. Hay un problema con Japón por la estadía del ex presidente Fujimori en ese país. Sería una ironía que Fujimori, que hizo tanto en la última 
década para acercar el Perú a Japón, se pueda convertir en un obstáculo para esto. Esperemos que las buenas relaciones de país a país se mantengan. Pero algo que probablemente ocurrirá es que la ingente ayuda japonesa al Perú de la última década disminuirá en forma independiente de lo que suceda con Fujimori, pues Japón tiene serios poblemos fiscales y de hecho su ayuda oficial al extranjero ha empezado a disminuir desde hace dos años.

En todo caso, Japón, China y Rusia, tres de los más grandes mercados para nuestros productos y potencias mundiales en la región asiática, y socios nuestros en el APEC, presentan un desafío para el Perú. Éste es cómo venderles más, atraer inversión desde ellos y consolidar nuestra relación diplomática y política en la tarea de diversificar al país de nuestra tradicional dependencia de los mercados norteamericano yeuropeo.

\section{NOTA}

1 En el APEC a los países miembros se les denomina economías y las reuniones de los Jefes de Estado son denominadas reunión de Líderes Económicos.

\section{BIBLIOGRAFÍA}

\section{Aduanas del Perú}

Página web oficial: www.aduanet.gob.pe.

\section{APEC}

Página web oficial: www.apecsec.org.sg.

\section{Aquino, Carlos}

Relaciones Perú - Japón: Diplomacia, Inmigración, Economía y Política.

Lima, Grafica Biblos, febrero de 1994.

\section{Aquino, Carlos}

"Experiencias de procesos de Integración Económica: El Pacto Andino, la Unión Europea y la ASEAN", en Revista de la Facultad de Ciencias Económicas de la Universidad Nacional Mayor de SanMarcos, julio de 1997, Lima, Perú.

\section{Aquino, Carlos}

- Introducción a la Economía Asiática - El desarrollo económico del Asia Oriental y Lecciones para el Perú. Perú, UNMSM, 2000.

\section{ASEAN}

Página web oficial: http://www. aseansec.org

\section{Proinversion}

Página web: wwul.mef.gob.pe/peruinuel

\section{Torres Cuzcano, Víctor}

ElPerúfrente a la Cuenca del Pacífico. Perú, IPRI-PNUD, 1991. 